\title{
The Assessment of Visuospatial Skills and Verbal Fluency in the Diagnosis of Alzheimer's Disease
}

Andras Horvath ( $\square$ andras.horvath.semmelweis@gmail.com )

Semmelweis University

Dalida Berente

Semmelweis University

Anita Kamondi

Országos Idegsebészeti Tudományos Intézet

\section{Research Article}

Keywords: AD, diagnosis, patients, Impairment

Posted Date: December 21st, 2020

DOI: https://doi.org/10.21203/rs.3.rs-129291/v1

License: (c) (1) This work is licensed under a Creative Commons Attribution 4.0 International License. Read Full License 


\section{Abstract}

Introduction: In the diagnosis of Alzheimer's disease (AD), examining memory is predominant. Our aim was to analyse the potential role of various cognitive domains in the cognitive evaluation of AD.

Methods: 52 individuals with AD underwent neuropsychological evaluation including Addenbrooke's Cognitive Examination (ACE). Patients were selected in three groups based on disease duration in years (y) (Group 1: $\leq 2 y n=15 ;$ Group 2: 2-4y n=26, Group 3: $\geq 4 y$ n=11). Covariance weighted intergroup comparison was performed on global cognitive score and subscores of cognitive domains. Spearman's rho was applied to study the correlation between cognitive subscores and disease duration.

Results: Significant difference was found between ACE total scores among groups $(\chi 2=16,03 p<0,001)$ with a high negative correlation $(r=-0,54 p<0,001)$. With longer disease duration the visuospatial and memory subscores of ACE significantly decreased ( $\chi 2=28,36 p<0,001$; and $f=12,05 p<0,001$ respectively). In the early phase of cognitive decline verbal fluency and memory were equally impaired $(p>0.05)$. Visuospatial score showed strong negative correlation with disease duration (r:-0.73).

Conclusion: Impairment of verbal fluency seems to have similar diagnostic potential in the early identification of Alzheimer's disease as memory decline. Visuospatial assessment might be a good marker to monitor the progression of cognitive decline.

\section{Introduction}

Currently there are around fifty million patients worldwide living with major neurocognitive disorders. This number is expected to triple by 2050, placing tremendous socio-economic and medical burden on the society. Alzheimer's disease (AD) is the leading cause of cognitive decline in the elderly, accounting for two thirds of dementia cases worldwide [1]. AD is characterised by gradual decline of cognitive function, affecting the social and communication skills as well. The histopathological hallmarks of the disease are the presence of extracellular amyloid plaques and intracellular neurofibrillary tangles [2]. The initially affected neural structures are the hippocampus and the entorhinal cortex [3]. These areas have crucial role in episodic memory, spatial orientation, and visuospatial abilities.

The progression of the disease follows a pattern starting with mild cognitive impairment (MCl) as the prodromal phase of $A D$ which may appear years prior to the dementia diagnosis of a patient. In most patients, $\mathrm{MCl}$ is characterised by memory complaints (amnestic type $\mathrm{MCl}$ ) [4]. According to the current DSM-V diagnostic guideline, short-term memory impairment becomes significant and learning difficulties appear in mild $A D$ [5]. In moderate $A D$, other cognitive domains are involved as well including language difficulties and impaired orientation. In severe $A D$, all cognitive domains are severely affected, communication skills and self-reliance are lost [6].

Current diagnostic guidelines advise the evaluation of a patient's medical history, clinical examination to test mental status as core tests and cerebrospinal fluid analysis, neuroimaging using magnetic 
resonance imaging or positron emission tomography as supportive diagnostic markers [7]. Use of neuropsychological test batteries is recommended too (e.g. Rey Auditory Verbal Learning Test- RAVLT, Montreal Cognitive Assessment- MoCA, Addenbrooke Cognitive Examination- ACE, Alzheimer's Disease Assessment Scale-Cognitive Subscale- ADAS-Cog). These tests focus on assessing memory function and learning skills, while investigation of visuospatial abilities and verbal fluency is relatively less detailed [8] although they might hold significant diagnostic and prognostic potential as well [9] since they require organized activation of large neural networks [10-12].

We hypothesised that in $A D$ the severity of visuospatial- and verbal fluency performance decline is related to disease duration, as during the course of the neurodegenerative process more and more cortical areas involved in these functions become affected. Thus, our aim was to analyse the profile of cognitive impairment in AD patients with various disease duration exploring multiple cognitive domains (memory, orientation, attention, verbal fluency, language and visuospatial abilities) to assess their potential role in the early identification of $A D$ and in the follow-up of the progression of cognitive decline.

\section{Methods}

\section{Participants}

Fifty-two patients (31 male, 21 female, mean age 72,62 $\pm 7,57$ ) with AD were recruited from the Department of Neurology at the National Institute of Clinical Neurosciences in Budapest, Hungary. Informed written consent was obtained from each participant. The participants' diagnosis was given based on the guidelines of the National Institute on Aging and the Alzheimer's Association (NIA-AA). [13] We sorted the participants in three groups based on disease duration. Group $1(n=15,28,84 \%)$ included participants with disease duration up to two years, group $2(n=26)$ with disease duration of 2 to 4 years, and group $3(n=11)$ with disease duration of 4 years or more. Disease duration was calculated from the clinical diagnosis of AD. Heteroanamnestic data were also collected from family members and caregivers. Patients with a history of cognitive symptoms more than 2 years before the diagnosis of $A D$ were not included in the current analysis. All methods were carried out in accordance with relevant guidelines and regulations. All experimental protocols were approved by The Hungarian Medical Research Council (reference number of ethical approval: 024505/2015).

\section{Clinical testing}

The participants underwent detailed medical, neurological, physical examination, as well as routine blood checks including thyroid functions and vitamin B12 levels. All patients had structural brain magnetic resonance imaging (MRI). MRIs were analyzed with visual inspection and medial temporal lobe atrophy (MTA) score was calculated. MTA $=1$ shows that choroid fissure is slightly widened among the hippocampi, MTA = 2 shows mild enlargement of temporal horn and mild loss of hippocampal height, MTA = 3 indicates moderate enlargement of temporal horn and moderate loss of hippocampal height, while MTA $=4$ shows the marked enlargement of temporal horn and the loss of internal hippocampal structure. [14] We determined all the known risk factors of cognitive decline as exclusion criteria. Such 
risk factors included: untreated vitamin B12 deficiency or hypothyroidism, liver disease, renal insufficiency, alcohol or substance abuse, psychoactive drugs influencing cognitive function except for anti-dementia medications, clinically significant brain lesions (white matter infarcts, stroke, severe periventricular white matter disease) demyelinating conditions, head injury with loss of consciousness, hydrocephalus, schizophrenia, major depression, electroconvulsive therapy, HIV infection, syphilis or prior central nervous system infections.

\section{Neuropsychology}

All participants took part in neuropsychological evaluation. The assessments were conducted by trained neurologists or neuropsychologists. The language of evaluation was Hungarian. We selected the Hungarian validated version of Addenbrooke's Cognitive Examination (ACE) [15] to assess cognitive function. It is known for its high specificity and sensitivity in the diagnosis of cognitive disorders [16]. It tests six cognitive domains: orientation, attention, memory, verbal fluency, language and visuospatial abilities with a maximum score of $10 ; 8 ; 35 ; 14 ; 28 ; 5$ respectively, resulting in a maximum total score of 100. A total score of 83 set as cut off score has a $82 \%$ sensitivity at age $>65$ [17]. Calculating the ratio of verbal fluency $(\mathrm{V})$ and language $(\mathrm{L})$ subscores/orientation $(\mathrm{O})$ and delayed recall memory $(\mathrm{M})$ subscores (VLOM ratio: $(V+L) /(O+M)$ ) enables differentiation between $A D$ and frontotemporal dementia (FTD). The normal range of VLOM ratio is between 2.2 and 3.2. A value higher than 3.2 indicates Alzheimer-type dementia, while a value lower than 2.2 demonstrates frontotemporal type dementia. Visuospatial abilities are tested by asking the participant to copy two overlapping pentagons, to copy a cube and to draw a clock face with the hands set at a specified time. Verbal fluency is analyzed with two tasks to examine categorical fluency (naming of animals) and phonemic fluency (listing words starting with the letter " $\mathrm{m}$ "). Furthermore, the Mini-Mental State Examination (MMSE) is incorporated in the ACE enabling dementia severity assessment. Its total score ranges from 0 to 30 , with higher scores indicating better cognitive performance.

Depression and anxiety may impair cognitive function $[18,19]$. To reduce such effects, we included the Beck Depression Inventory II (BDI-II) and Spielberger State and Trait Anxiety Inventory (STAI) in our test battery. A BDI-II score of less than 13 demonstrates minimal depression. Scores between 14 and 19 indicate mild depression, those between 20 and 28 refer to moderate depression, while a score of 29 or higher demonstrates severe depression. A low level of anxiety is indicated by a score of 45 or less for both state and trait anxiety. Participants with a BDI-II score of $>13$ or a STAl score of $>45$ were excluded from our analysis.

\section{Data analysis}

The statistical analysis was carried out with the alpha level set at 0,05. Data distribution was tested using Shapiro-Wilk test. To test for significant differences (for intergroup comparisons) in demographic variables (e.g. age, years of education) one-way ANOVA and Kruskall-Wallis tests were used as parametric and non-parametric tests respectively based on the distribution of data. Due to the nonparametric distribution of data Spearman's rho was used to study the correlation between disease 
duration (years) and cognitive function represented by the ACE total score. Between-group differences for ACE subscores were tested with covariance weighted (age, sex, disease onset and disease duration) ANOVA and Kruskal-Wallis tests. Tukey test was applied for post-hoc analysis. Spearman correlation was applied for the connection of ACE subscores and disease duration. For within group analysis including normalized ACE subscores, normalization was applied with the achieved score in each cognitive domain divided with a maximum possible score of the same cognitive domain (e.g., 7/28 in language cognitive domain resulted in 0.25). Friedmann test was applied with Wilcoxon-signed rank test because of the nonparametric distribution of data. IBM SPSS 20 software was used for statistical analysis.

\section{Results}

\section{Demographic data}

Altogether 52 individuals (31 male: 59,62\%, 21 females: 40,38\%) with Alzheimer's disease diagnosis participated in the study. The participant's mean age was 72,62 $\pm 7,57$ years. Their mean duration of education was $13,00 \pm 2,56$ years. All patients showed the typical characteristic of cortical atrophy (bifrontal-bitemporal atrophy with reduced hippocampi). All patients had medial temporal lobe atrophy score $\geq 3$.

Group 1 ( $n=15$; disease duration of no more than 2 years) included 11 male $(73,33 \%)$ and 4 female $(26,67 \%)$ participants with a mean age of $70,07 \pm 9,5$ years. In group $2(n=26$; disease duration of 2 to 4 years) there were 15 male $(57,69 \%)$ and 11 female $(42,31 \%)$ participants. Their mean age was 73,46 \pm 6,85 years. In group $3(n=11$; disease duration longer than 4 years) 5 male $(45,45 \%)$ and 6 female $(54,55 \%)$ participants were selected, with a mean age of 74,09 $\pm 5,72$ years. We studied between-group differences in sex, age, age at disease onset, education level, disease duration, ACE total score and VLOM ratio (Table 1). Kruskal-Wallis test showed significant differences in disease duration, ACE total score and MMSE score between the three groups (all $p$ values $<0,001$ ). 
Table 1

Demographic and clinical data of participants.

\begin{tabular}{|c|c|c|c|c|c|}
\hline Parameter & Total & Group 1 & Group 2 & Group 3 & $\begin{array}{l}\mathrm{p}- \\
\text { value }\end{array}$ \\
\hline Participants (n) & 52 & 15 & 26 & 11 & - \\
\hline Male, n (\%) & $31(59,6 \%)$ & $11(73,3 \%)$ & $15(57,7 \%)$ & $5(45,5 \%)$ & 0,17 \\
\hline Female, n (\%) & $21(40,4 \%)$ & $4(26,7 \%)$ & $11(42,3 \%)$ & $6(54,5 \%)$ & 0.053 \\
\hline $\begin{array}{l}\text { Age (years) median ratio (IQ1- } \\
\text { IQ3) }\end{array}$ & $\begin{array}{l}73,0(69,3- \\
77,0)\end{array}$ & $\begin{array}{l}71,0(63,0- \\
77,0)\end{array}$ & $\begin{array}{l}73,5(71,0- \\
76,5)\end{array}$ & $\begin{array}{l}73,0(70,0- \\
79,0)\end{array}$ & 0,40 \\
\hline $\begin{array}{l}\text { Age at disease onset (years) } \\
\text { mean } \pm \text { SD }\end{array}$ & $69,8 \pm 7,4$ & $68,7 \pm 9,4$ & $70,5 \pm 6,9$ & $69,6 \pm 5,9$ & 0,78 \\
\hline Education (years) & $\begin{array}{l}12,0(12,0- \\
17,0)\end{array}$ & $\begin{array}{l}12,0(12,0- \\
17,0)\end{array}$ & $\begin{array}{l}12,0(12,0- \\
17,0)\end{array}$ & $\begin{array}{l}12,0(10,0- \\
12,0)\end{array}$ & 0,25 \\
\hline $\begin{array}{l}\text { Disease duration (years) median } \\
\text { ratio (IQ1-IQ3) }\end{array}$ & $\begin{array}{l}3,0(2,0- \\
3,0)\end{array}$ & $\begin{array}{l}1,0(0,0- \\
2,0)\end{array}$ & $\begin{array}{l}3,0(2,0- \\
4,0)\end{array}$ & $\begin{array}{l}4,0(4,0- \\
5,0)\end{array}$ & $\dot{0}, 001$ \\
\hline $\begin{array}{l}\text { ACE total score median ratio } \\
\text { (IQ1-IQ3) }\end{array}$ & $\begin{array}{l}67,0(55,3- \\
75,0)\end{array}$ & $\begin{array}{l}72,0(67,0- \\
79,0)\end{array}$ & $\begin{array}{l}67,5(55,0- \\
76,3)\end{array}$ & $\begin{array}{l}50,0(44,0- \\
59,0)\end{array}$ & $\begin{array}{l}<, 001 \\
0,1\end{array}$ \\
\hline VLOM median ratio (IQ1-IQ3) & $\begin{array}{l}3,4(3,2- \\
4,1)\end{array}$ & $\begin{array}{l}3,4(3,2- \\
3,9)\end{array}$ & $\begin{array}{l}3,5(3,2- \\
4,3)\end{array}$ & $\begin{array}{l}3,4(3,3- \\
3,6)\end{array}$ & 0,995 \\
\hline MMSE median (IQ1-IQ3) & $\begin{array}{l}20,0(16,0- \\
23,0)\end{array}$ & $\begin{array}{l}25,0(22,0- \\
25,0)\end{array}$ & $\begin{array}{l}19,5(16,0- \\
21,3)\end{array}$ & $\begin{array}{l}15,0(12,0- \\
18,0)\end{array}$ & $\iota_{0,001}$ \\
\hline $\begin{array}{l}\text { Orientation } \\
\text { median ratio (IQ1-IQ3) }\end{array}$ & $\begin{array}{l}7,0(6,0- \\
8,0)\end{array}$ & $\begin{array}{l}9,0(7,0- \\
10,0)\end{array}$ & $\begin{array}{l}7,0(6,0- \\
8,0)\end{array}$ & $\begin{array}{l}7,0(5,0- \\
8,0)\end{array}$ & 0,015 \\
\hline $\begin{array}{l}\text { Attention } \\
\text { median ratio (IQ1-IQ3) }\end{array}$ & $\begin{array}{l}6,0(4,3- \\
7,0)\end{array}$ & $\begin{array}{l}6,0(5,0- \\
7,0)\end{array}$ & $\begin{array}{l}6,5(5,0- \\
7,0)\end{array}$ & $\begin{array}{l}4,0(4,0- \\
7,0)\end{array}$ & 0,097 \\
\hline Memorymean \pm SD & $20,0 \pm 5,0$ & $22,2 \pm 3,5$ & $21,0 \pm 4,9$ & $14,6 \pm 3,2$ & $\dot{0}, 001$ \\
\hline Verbal fluency mean \pm SD & $8,5 \pm 2,5$ & $9,1 \pm 1,9$ & $8,6 \pm 2,4$ & $7,5 \pm 3,4$ & 0,27 \\
\hline Language mean $\pm S D$ & $20,4 \pm 4,6$ & $22,9 \pm 2,5$ & $20,3 \pm 5,0$ & $17,3 \pm 4,0$ & 0,006 \\
\hline $\begin{array}{l}\text { Visuospatial abilities median } \\
\text { ratio (IQ1-IQ3) }\end{array}$ & $\begin{array}{l}3,0(2,0- \\
4,0)\end{array}$ & $\begin{array}{l}4,0(4,0- \\
5,0)\end{array}$ & $\begin{array}{l}2,5(2,0- \\
3,0)\end{array}$ & $\begin{array}{l}1,0(1,0- \\
2,0)\end{array}$ & $\begin{array}{l}<, 001 \\
0\end{array}$ \\
\hline
\end{tabular}

Statistical tests applied were Chi-square for sex, ANOVA for parametric and Kruskal-Wallis for nonparametric statistics. Significant differences are present in disease duration, ACE total score and MMSE score between the three groups (all $p$ values $<0,001$ ). One-way ANOVA analysis was used for betweengroup differences in memory, language and verbal fluency. Kruskal-Wallis test was used for between- 
group differences in orientation, attention and visuospatial abilities.SD: standard deviation; MMSE: MiniMental State Examination IQ1-IQ3: interquartile range

\section{Relationship between ACE total score and disease duration}

Spearman's rho showed a significant negative correlation between ACE total scores and disease duration $(p<0,001 ; r:-0,544)$. To support this finding a one-way ANOVA was used confirming significant group effect on total ACE score ( $F=12,14 ; p<0,001)$.

\section{Between-group differences between ACE subscores}

One-way ANOVA was used to test within-group differences between subscores of memory, language and verbal fluency data (Table 1). Significant between-group differences were found for memory $(F=12,05 ; p$ $<0,001)$ and language $(F=5,62 ; p=0,006)$. Kruskal-Wallis test was applied to study between-group differences between subscores of orientation, attention and visuospatial abilities (Table 1). Significant between-group differences were found for visuospatial abilities $(\chi 2=28,36 ; p<0,001)$ and orientation ( $\chi 2$ $=8,42 ; p=0,015)$. Age, sex, disease onset and disease duration did not have significant modifier effect on between group differences (all p values >0.05). Post-hoc analysis revealed that Group 1 differs from Group 2 and Group 3 in orientation skills (all p values < 0.05) but Group 2 and Group3 are not significantly different (p:0.899). As for memory, difference between Group 1 and Group 2 was not significant (p:0.63), while Group 2 and Group 3 showed significant differences $(p<0.001)$. Regarding language, only Group 3 and Group 1 differed (p: 0.004). In visuospatial skills all groups differed significantly (all $p$ values $<0.05$ ) (Fig. 1).

\section{Relationship between ACE subscores and disease duration}

Spearman's rho was applied to test the relationship between all six ACE subscores and disease duration (Table 2). Significant negative correlation was found between disease duration and orientation $(p=0,01$; $r:-0,35)$ memory $(p<0,001 ; r:-0,52)$, language $(p<0,001 ; r:-0,48)$ and visuospatial abilities $(p<0,001$; r:-0,73) (Fig. 2).

Table 2

Correlation analysis between ACE subscores and disease duration using Spearman's rho.

\begin{tabular}{|lllllll|}
\hline & Orientation & Attention & Memory & Verbal fluency & Language & Visuospatial abilities \\
\hline $\mathrm{p}$ & 0,01 & 0,09 & $<0,001$ & 0,047 & $<0,001$ & $<0,001$ \\
\hline $\mathrm{r}$ & $-0,35$ & $-0,24$ & $-0,52$ & $-0,28$ & $-0,48$ & $-0,73$ \\
\hline
\end{tabular}

Within-group differences between ACE subscores

We applied the Friedman test for within-group difference analysis between ACE subscores. Differences between the normalized subscores are shown in Fig. 3. We found significant differences (all p's < 0.001 ) between the subscores in all groups (Table 3). Tukey test was applied for posthoc analysis. 
In Group 1, normalized subscore of orientation was significantly higher than memory $(p=0.003)$ and verbal fluency $(p=0.002)$. Normalized subscore of attention was significantly higher than memory $(p=$ $0.017)$ and verbal fluency $(p=0.01)$. Normalized subscore for memory was significantly reduced compared to language $(p=0.003)$ and visuospatial skills $(p=0.004)$; verbal fluency was significantly lower than language $(p=0.002)$ and visuospatial abilities $(p=0.003)$.

In Group 2, normalized subscore of orientation was significantly higher than memory $(p=0,006)$, verbal fluency (p:0,039) and visuospatial abilities (p:0,001); and significantly lower than attention (p:0,034). Normalized subscore of attention was significantly higher than memory $(p<0,001)$, verbal fluency $(p<$ $0,001)$ and visuospatial abilities $(p<0,001)$. Normalized subscore of memory was significantly higher than visuospatial abilities ( $p: 0,011)$ and significantly reduced compared to language $(p: 0,003)$. Normalized subscore of verbal fluency was significantly higher than visuospatial abilities $(\mathrm{p}: 0,09)$ and significantly lower than language (p:0,05). Normalized subscore of language was significantly higher than visuospatial abilities $(\mathrm{p}: 0,001)$.

In Group 3, normalized subscore of orientation was significantly higher than memory $(0,003)$ and visuospatial abilities ( $\mathrm{p}: 0,005)$. Normalized subscore of attention was significantly higher than memory $(p: 0,006)$ and visuospatial abilities $(p=0,005)$. Normalized subscore of memory was significantly reduced compared to language $(p=0,003)$. Normalized subscore of verbal fluency was significantly higher than visuospatial abilities ( $\mathrm{p}: 0,008)$. Normalized subscore of language was significantly higher than visuospatial abilities (p:0,008). 
Table 3

Normalized ACE subscores for orientation, attention, memory, verbal fluency, language and visuospatial abilities per group.

\begin{tabular}{|lllll|}
\hline \multirow{3}{*}{ Orientation } & & Group 1 & Group 2 & Group 3 \\
\hline Attention & Mean & 0,85 & 0,69 & 0,66 \\
\cline { 2 - 5 } & SD & 0,18 & 0,15 & 0,14 \\
\hline Memory & Mean & 0,76 & 0,76 & 0,61 \\
\cline { 2 - 5 } & SD & 0,17 & 0,20 & 0,19 \\
\hline Verbal fluency & Mean & 0,63 & 0,60 & 0,42 \\
\hline Language & Mean & 0,65 & 0,61 & 0,53 \\
\cline { 2 - 5 } & SD & 0,14 & 0,17 & 0,24 \\
\hline Visuospatial abilities & Mean & 0,82 & 0,73 & 0,62 \\
\cline { 2 - 5 } & SD & 0,10 & 0,18 & 0,14 \\
\cline { 2 - 5 } & SD & 0,81 & 0,49 & 0,26 \\
\cline { 2 - 5 } & & 0,14 & 0,21 & 0,20 \\
\hline
\end{tabular}

\section{Discussion}

Our study involved 52 AD patients divided into three groups based on the length of disease duration. Our main findings are that verbal fluency disturbance is comparable to memory impairment in the diagnosis of $A D$ in the initial phase and testing visuo-spatial abilities might be an appropriate method for monitoring disease progression.

Our analysis using correlation and between group approaches showed that patients with a longer disease duration have lower ACE global scores being in line with the current literature and confirming the fact that $A C E$ indicates well the severity of $A D[20]$ and global decline in cognition most frequently shows a linear pattern in $A D[21,22]$.

While significant reduction in ACE subscores were present in a more advanced disease stage in case of memory, language, orientation, attention, and visuospatial abilities; the pattern of the impairment of different cognitive domains demonstrated prominent differences. Other studies also showed that selective analysis of cognitive subdomains might reveal various trajectories of cognitive decline in $A D$ [22]. Memory impairment is clearly the most well-known hallmark of AD; however, controversial results exist. Some reports suggest that declined memory functions associate with the early phase of $A D[23,24]$ while others support the appearance of prominent memory impairment in the advanced phase of 
cognitive decline $[6,25]$. Our findings might reveal a deeper insight to the proposed problem. Our results show that memory is the most affected cognitive domain already in the early course of the disease having significantly lower normalized score (0.63) than any other subscores except verbal fluency $(0.65)$. However, during the first 2-3 years after the diagnosis the subsequent decrease of memory scores is not prominent (Group 1 and 2 do not differ significantly) suggesting that sequential memory testing might not be the ideal tool to sensitively detect the progression of the cognitive decline. However, memory functions show rapid decline after 4 years of disease onset supporting the earlier data demonstrating that memory impairment is predominantly evident in the later stages of $A D$ [25]. This might suggest that while severity of cognitive decline is continuously increasing with the duration of the disease, memory shows gradual reduction. We also found that verbal fluency was as severely compromised at the early stage of $A D$ as memory. Other reports also highlighted that verbal fluency is impaired even in amnestic type $\mathrm{MCl}$ [26], in the preclinical phase or mild phase of $A D$ [27]. Ideal verbal fluency tests were not developed for routine screening of cognitive decline since there are controversial results: some studies propose that semantic (category) fluency might be an ideal tool for the early screening of dementia [2830] while others demonstrated the superiority of phonemic (letter) fluency [26]. However, a meta-analysis of 153 studies with 15990 participants proposed that semantic deficit is more prominent than phonemic [31]. It is supported by neuroimaging studies as well showing that semantic (categorical) fluency and word collection with similar phonemic features both require distinct activation of fronto-temporal networks including bilateral inferior temporal gyri, prefrontal areas, temporal gyri of dominant hemisphere and superior frontal areas of subdominant hemisphere [11, 12]; however, hippocampus has a dominant role in the maintenance of normal semantic fluency functions [32].

Our correlation analysis between disease duration and ACE subscores showed that patient with longer duration perform worse in orientation, memory, language and visuospatial abilities. Visuospatial score showed the remarkably strong negative correlation with disease duration (r:-0.73) drawing special attention to this cognitive domain. Visuospatial skills are used to remember directions, addresses, and layout of familiar places. Visuospatial abilities are tested by asking the patient to copy two diagrams; to draw a clock face with the hands set at a specified time; to count sets of dots; and to recognize four letters which are partially obscured. Studying visuospatial abilities and their involvement in AD is a growing area of research since it involves many neural networks and those are frequently affected in $A D$ as well. Object identification and localisation activates the superior parietal lobe, the posterior parietal cortex, parieto-occipital junction, entorhinal cortex, hippocampal networks and premotor areas [10]. Furthermore, it was found that visuospatial function is impaired in $A D$ even in the early stages with significant difference between the controls and patients [10]. In accordance with the previous findings, Beretta et al found temporo-parietal hypometabolism in AD patients using FDG-PET [33]. In addition, the involvement of anterior visual pathway using functional MRI appears at the predementia clinical stage of $A D$ [34]. Although problems in visuospatial abilities are less well characterised symptoms of $A D$ compared to memory impairment [9], visuospatial function monitoring could be ideal for deciding whether cognitive decline is progressive or not. Furthermore, it might be a useful cognitive test for outcome measures of drug trials. 
There are limitations to our study. Firstly, positron emission tomography, cerebrospinal fluid analysis or genetic testing were not applied in the current experiment. Furthermore, cognitive decline might appear years preceding the diagnosis of $A D$, so disease duration might vary among the examined patients. We involved patients with short history of cognitive decline before the diagnosis of $A D$ based on the reports of caregivers, however opinion of family members could be subjective. The strength of our study is the rigorous patient selection and the extensive application of different diagnostic methods.

\section{Conclusion}

$A D$ is the leading cause of dementia in the elderly. However, only sixteen percent of the elderly receive regular cognitive evaluation [35]. Unfortunately the estimated extent of missed or delayed diagnosis of $A D$ is substantial [36]. Impairment of verbal fluency seems to have crucial diagnostic potential in the early identification of $A D$. Visuospatial abilities have been found to be impaired in $A D$ even in preclinical stages and are considered to hold diagnostic potential $[9,37]$. Furthermore, they might have a potential role in the assessment of progression of cognitive decline and might be ideal in the validation phase of drug trials.

\section{Declarations}

\section{Author contributions}

\begin{tabular}{|llll|}
\hline Name & $\begin{array}{l}\text { Location } \\
\begin{array}{l}\text { Dalida } \\
\text { Borbala } \\
\text { Berente }\end{array}\end{array} \begin{array}{l}\text { National } \\
\text { Institute of } \\
\text { Clinical } \\
\text { Neurosciences, } \\
\text { Budapest }\end{array}$ & Author & $\begin{array}{l}\text { Contribution } \\
\text { She was responsible for data management and the } \\
\text { conduction of statistical analysis. She contributed to the } \\
\text { writing of the manuscript. }\end{array}$ \\
\hline $\begin{array}{l}\text { Anita } \\
\text { Kamondi }\end{array}$ & $\begin{array}{l}\text { National } \\
\text { Institute of } \\
\text { Clinical } \\
\text { Neurosciences, } \\
\text { Budapest }\end{array}$ & Author & $\begin{array}{l}\text { She was involved in the recruitment of patients, and in the } \\
\text { design of the study protocol. She contributed to the } \\
\text { correction of the manuscript. }\end{array}$ \\
$\begin{array}{l}\text { Andras } \\
\text { Attila } \\
\text { Horvath }\end{array}$ & $\begin{array}{l}\text { National } \\
\text { Institute of } \\
\text { Clinical } \\
\text { Neurosciences, } \\
\text { Budapest }\end{array}$ & Author & $\begin{array}{l}\text { He performed neuropsychological assessments, evaluated } \\
\text { the results and concluded the major findings. He } \\
\text { contributed to the writing of the manuscript. }\end{array}$ \\
\hline
\end{tabular}

\section{Acknowledgements}


Our study was supported by National Brain Research Program I, II (KTIA_NAP_13-1-2013-0001; 20171.2.1-NKP-2017-00002), Hungarian Scientific Research Fund 2019 (PD-132652), Janos Bolyai Research Scholarship of the Hungarian Academy of Sciences (bo_78_20_2020). This is an EU Joint ProgrammeNeurodegenerative Disease Research (JPND) project. The project is supported through the following funding organisation under the the aegis of JPND- www.jpnd.eu (National Research, Development and Innovation, Hungary, 2019-2.1.7-ERA-NET-2020-00006).

\section{Additional Information (including a Competing Interests Statement)}

\section{Competing Interests}

The authors declare no competing interests.

\section{Data availability}

The data that support the findings of this study and not presented in this article are available on request from the corresponding author.

\section{References}

1. C., P., World Alzheimer Report 2018 - The state of the art of dementia research: New frontiers. London: Alzheimer's Disease International, 2018.

2. Reitz, C., C. Brayne, and R. Mayeux, Epidemiology of Alzheimer disease. Nature reviews. Neurology, 2011. 7,(3): p. 137-152.

3. Braak, H. and E. Braak, Neuropathological stageing of Alzheimer-related changes. Acta Neuropathol, 1991. 82,(4): p. 239-59.

4. Mistridis, P., S. Krumm, A. U. Monsch, M. Berres, and K. I. Taylor, The 12 Years Preceding Mild Cognitive Impairment Due to Alzheimer's Disease: The Temporal Emergence of Cognitive Decline. $J$ Alzheimers Dis, 2015. 48,(4): p. 1095-107.

5. Association, A. P., Diagnostic and statistical manual of mental disorders, 5th ed, 2013: American Psychiatric Association Publishing.

6. Förstl, H. and A. Kurz, Clinical features of Alzheimer's disease. European Archives of Psychiatry and Clinical Neuroscience, 1999. 249,(6): p. 288-290.

7. McKhann, G. et al., Clinical diagnosis of Alzheimer's disease. Report of the NINCDS-ADRDA Work Group* under the auspices of Department of Health and Human Services Task Force on Alzheimer's Disease, 1984. 34,(7): p. 939-939.

8. Collie, A. and P. Maruff, The neuropsychology of preclinical Alzheimer's disease and mild cognitive impairment. Neurosci Biobehav Rev, 2000. 24,(3): p. 365-74.

9. Salimi, S. et al., Can visuospatial measures improve the diagnosis of Alzheimer's disease? Alzheimers Dement (Amst), 2018. 10: p. 66-74. 
10. Quental, N. B., S. M. Brucki, and O. F. Bueno, Visuospatial function in early Alzheimer's disease-the use of the Visual Object and Space Perception (VOSP) battery. PLoS One, 2013. 8,(7): p. e68398.

11. Ghanavati, E., M. A. Salehinejad, V. Nejati, and M. A. Nitsche, Differential role of prefrontal, temporal and parietal cortices in verbal and figural fluency: Implications for the supramodal contribution of executive functions. Scientific Reports, 2019. 9,(1): p. 3700.

12. Melrose, R. et al., The neural correlates of naming and fluency deficits in Alzheimer's disease: An FDG-PET study. International journal of geriatric psychiatry, 2009. 24: p. 885-93.

13. McKhann, G. M. et al., The diagnosis of dementia due to Alzheimer's disease: recommendations from the National Institute on Aging-Alzheimer's Association workgroups on diagnostic guidelines for Alzheimer's disease. Alzheimers Dement, 2011. 7,(3): p. 263-9.

14. Duara, R. et al., Medial temporal lobe atrophy on MRI scans and the diagnosis of Alzheimer disease. Neurology, 2008. 71,(24): p. 1986-92.

15. Stachó, L., R. Dudás, R. Ivády, and G. J. P. H. Kothencz, és Janka Z.(2003). Addenbrooke’s Kognitív Vizsgálat: a magyar változat kifejlesztése. 18,(4): p. 226-240.

16. Dudas, R. B., G. E. Berrios, and J. R. Hodges, The Addenbrooke's cognitive examination (ACE) in the differential diagnosis of early dementias versus affective disorder. Am J Geriatr Psychiatry, 2005. 13, (3): p. 218-26.

17. Mathuranath, P. S., P. J. Nestor, G. E. Berrios, W. Rakowicz, and J. R. Hodges, A brief cognitive test battery to differentiate Alzheimer's disease and frontotemporal dementia. Neurology, 2000. 55,(11): p. 1613-20.

18. Kramer, S. I. and B. V. Reifler, Depression, dementia, and reversible dementia. Clinics in geriatric medicine, 1992. 8,(2): p. 289-297.

19. Seignourel, P. J., M. E. Kunik, L. Snow, N. Wilson, and M. Stanley, Anxiety in dementia: a critical review. Clin Psychol Rev, 2008. 28,(7): p. 1071-82.

20. Hodges, J. R. and A. J. Larner, Addenbrooke's Cognitive Examinations: ACE, ACE-R, ACE-III, ACEapp, and M-ACE, in Cognitive Screening Instruments. 2017. p. 109-137.

21. Suh, G. H., Y. S. Ju, B. K. Yeon, and A. Shah, A longitudinal study of Alzheimer's disease: rates of cognitive and functional decline. Int J Geriatr Psychiatry, 2004. 19,(9): p. 817-24.

22. Wilkosz, P. A. et al., Trajectories of cognitive decline in Alzheimer's disease. Int Psychogeriatr, 2010. 22,(2): p. 281-90.

23. Baudic, S. et al., Executive function deficits in early Alzheimer's disease and their relations with episodic memory. Arch Clin Neuropsychol, 2006. 21,(1): p. 15-21.

24. Sperling, R. A. et al., Functional alterations in memory networks in early Alzheimer's disease. Neuromolecular Med, 2010. 12,(1): p. 27-43.

25. de Boer, C., F. Mattace-Raso, J. van der Steen, and J. J. Pel, Mini-Mental State Examination subscores indicate visuomotor deficits in Alzheimer's disease patients: A cross-sectional study in a Dutch population. Geriatr Gerontol Int, 2014. 14,(4): p. 880-5. 
26. Murphy, K., J. Rich, and A. Troyer, Verbal fluency patterns in amnestic mild cognitive impairment are characteristic of Alzheimer's type dementia. Journal of the International Neuropsychological Society: JINS, 2006. 12: p. 570-4.

27. Clark, L. et al., Longitudinal Verbal Fluency in Normal Aging, Preclinical, and Prevalent Alzheimer's Disease. American journal of Alzheimer's disease and other dementias, 2009. 24: p. 461-8.

28. Gomez, R. G. and D. A. White, Using verbal fluency to detect very mild dementia of the Alzheimer type. Arch Clin Neuropsychol, 2006. 21,(8): p. 771-5.

29. Pasquier, F., F. Lebert, L. Grymonprez, and H. Petit, Verbal fluency in dementia of frontal lobe type and dementia of Alzheimer type. Journal of neurology, neurosurgery, and psychiatry, 1995. 58: p. 81-4.

30. Monsch, A. U. et al., Comparisons of verbal fluency tasks in the detection of dementia of the Alzheimer type. Arch Neurol, 1992. 49,(12): p. 1253-8.

31. Henry, J. D., J. R. Crawford, and L. H. Phillips, Verbal fluency performance in dementia of the Alzheimer's type: a meta-analysis. Neuropsychologia, 2004. 42,(9): p. 1212-22.

32. Gleissner, U. and C. E. Elger, The hippocampal contribution to verbal fluency in patients with temporal lobe epilepsy. Cortex, 2001. 37,(1): p. 55-63.

33. Beretta, L. et al., Two distinct pathological substrates associated with MMSE-pentagons item deficit in DLB and AD. Neuropsychologia, 2019. 133: p. 107174.

34. Pelak, V. S. and W. Hills, Vision in Alzheimer's disease: a focus on the anterior afferent pathway. Neurodegener Dis Manag, 2018. 8,(1): p. 49-67.

35. 2019 Alzheimer's disease facts and figures. Alzheimer's \& Dementia, 2019. 15,(3): p. 321-387.

36. Bradford, A., M. E. Kunik, P. Schulz, S. P. Williams, and H. Singh, Missed and delayed diagnosis of dementia in primary care: prevalence and contributing factors. Alzheimer disease and associated disorders, 2009. 23,(4): p. 306-314.

37. Hawkins, K. M. and L. E. Sergio, Visuomotor impairments in older adults at increased Alzheimer's disease risk. J Alzheimers Dis, 2014. 42,(2): p. 607-21.

\section{Figures}



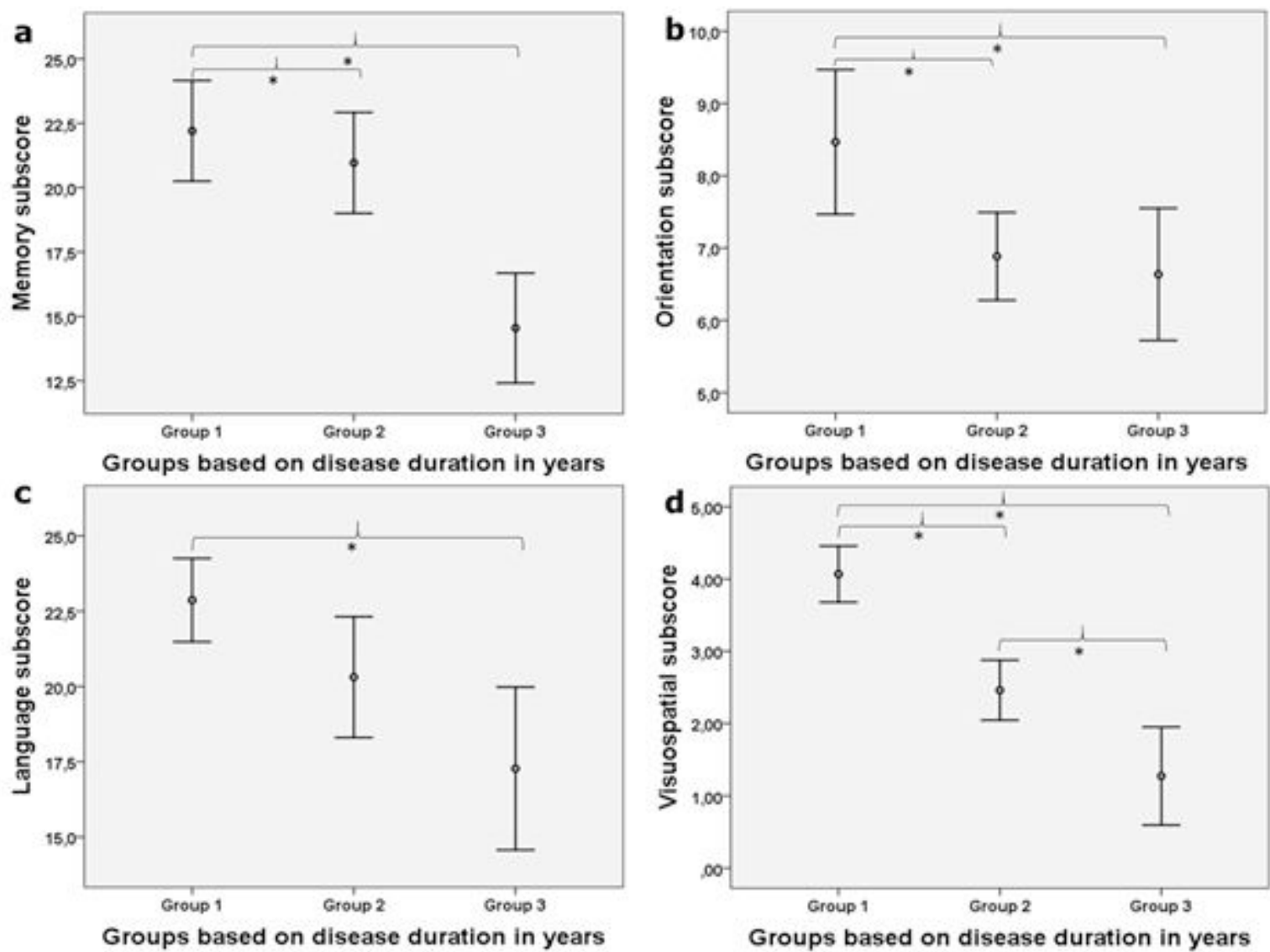

\section{Figure 1}

Between group differences for memory, orientation, language and visuospatial abilities subscores. Posthoc analysis revealed that Group 1 differs from Group 2 and Group 3 in orientation skills (all $p$ values<0.05) but Group 2 and Group3 are not significantly different (p:0.899). The difference in memory between Group 1 and Group 2 was not significant (p:0.63), while Group 2 and Group 3 showed significant differences ( $p<0.001)$. Only Group 3 and Group 1 differed ( $p: 0.004)$ in language. In visuospatial skills all groups differed significantly (all $p$ values<0.05). * indicates significant differences. 



Figure 2

Correlation analysis between ACE subscores and disease duration (in years) using Spearman's rho. Significant negative correlation was found between disease duration and orientation $(p=0,01 ; r:-0,35)$ memory $(p<0,001 ; r:-0,52)$, language $(p<0,001 ; r:-0,48)$ and visuospatial abilities $(p<0,001 ; r:-0,73)$.

Within-group difference between ACE subscores

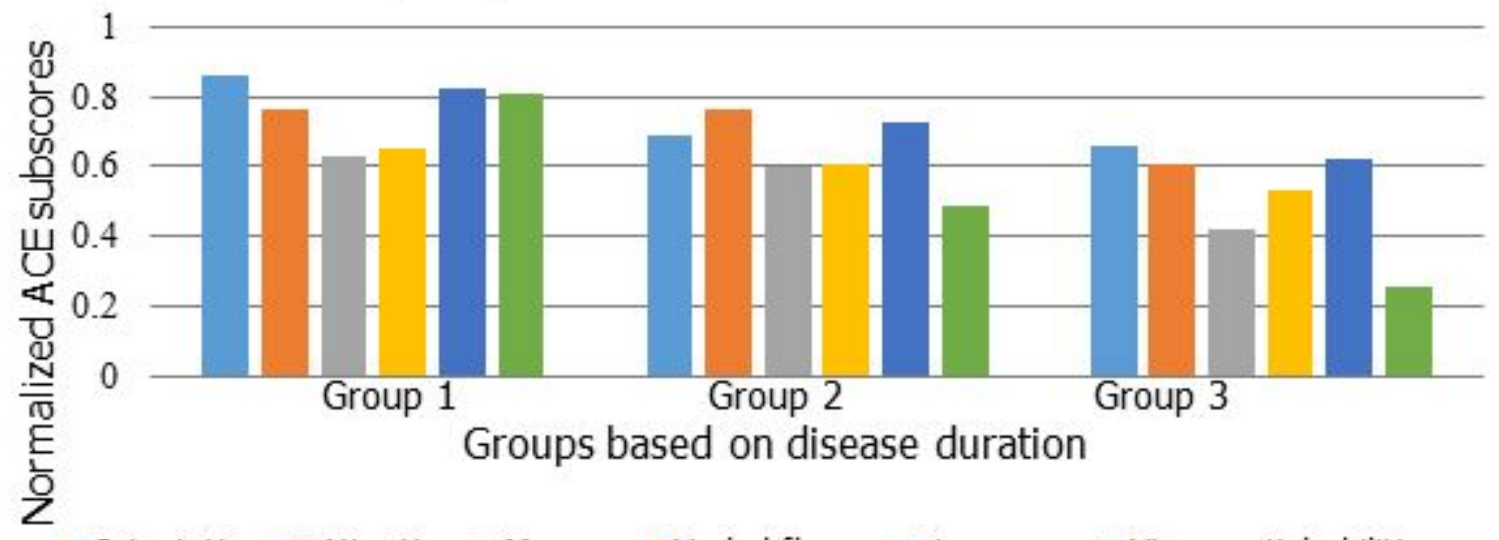

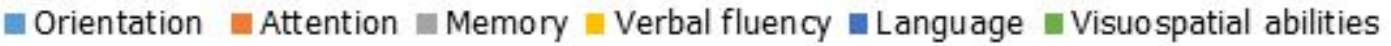

Figure 3 
Within-group difference analysis for normalized ACE subscores using Friedman test. 